\title{
The Effect of the Countercurrent Washing Process for KP Brown Pulp Stock Line ${ }^{* 1}$
}

\author{
Yoshitatsu Mori*3 \\ Consulting Dept. 2, Solution business Division, Yokogawa Solution Service Corporation*2
}

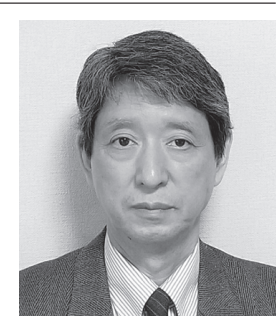

\begin{abstract}
The washing process of KP (Kraft pulp) brown pulp stocks, following to KP cooking continuous digester, is consist of a series of washing equipment. This multi stage washing process is not only to wash the brown pulp stocks effectively but also to recover KP cooking chemicals (expensive sodium compounds) and some wood lignin components that dissolved in the filtrated dilute black liquors. And the filtrated and extracted black liquors are send to the following KP causticizing process, and the chemicals are recovered finally.

In this KP washing process, "Countercurrent flow washing" strategy has been utilized in general, and expected to the washing process to achieve better washing states for the pulp stocks not to remain much chemicals in it. And, furthermore, they are required to be washed effectively with lesser amount of fresh water usage, and, at once expected to decrease the energy loads of the following black liquor evaporation process.

In this paper, a washing calculation model for this KP multi stage washing process that can simulate and estimate the chemical material balance was proposed. Next, utilizing the simulated results by this model and another "Cross flow washing strategy", that used simple fresh washing water flow lines were compared. As the result, the effect of the "Countercurrent flow washing" was confirmed from the superiorities of the simulated results of the recovered chemical amounts in each washing filtrate line, lost chemical amounts to be carried away attached to the brown pulp stocks and the variance of the recovered chemical consistencies etc.
\end{abstract}

Keywords : displacement washing, countercurrent flow washing, dilution factor, chemical loss, Kraft pulp

\section{Introduction}

"Material washing" is one of the typical basic operation that is used in wide areas of manufacturing processes, not limited in the pulp and paper industry. Although the

\footnotetext{
${ }^{* 1}$ This article was presented "The $24^{\text {th }}-2018$ JAPAN

TAPPI Pulping Conference"(10-11 May, 2018)

*22-9-32 Nakacho, Musashino-shi, Tokyo 180-8750, Japan

${ }^{* 3}$ E-mail : Yoshitatsu.Mori@jp.yokogawa.com
}

importance of the material washing is recognized well in the manufacturing processes, it seems very rare to be taken up as analysis problems, because the washing process is apt to be considered as a simple operation.

In the pulp manufacturing process, we must remove deposits and chemical contaminations that are attached to the brown pulp stocks by washing water (clear water), utilizing some washing equipment. And, at once, expected to attain high efficient washing with lesser water quantity as far as possible.

Plenty amounts of "washing filtrates" are generated 
accompanied with this washing process. Furthermore, those filtrates finally become recovered effluents (or waste water), and they are needed to execute some appropriate post-treatments. Take into consideration this complicated problem, to construct adequate washing process that are easy to treat and to recover the effluents in the later process is strongly desired.

In this paper, I proposed a simple washing model, that can calculate the material balance including chemical component amounts for KP washing processes. And the superiority of the "Countercurrent flow washing" strategy that had been used in the pulp and paper industry for a long time was confirmed through the numerical simulations by comparing the difference of the amount of the required clean fresh water for brown stock washing, washing states of the pulp stocks and the effect to the filtrates' properties etc. utilizing this model.

\section{Washing process of Kraft pulp}

2.1 KP Washing process and washing equipment

In $\mathrm{KP}$ continuous cooking digester, wood chips are separated to pulp fibers through the cooking reaction by dissolving the lignin components at high temperature and pressure, by adding white liquor (alkaline chemicals) that consist of $\mathrm{NaOH}$ and $\mathrm{Na}_{2} \mathrm{~S}$ etc. in main component.

And after the KP cooking process, the brown stock pulps have to wash and remove the chemicals and dissolved lignin components that are attached to it well in the next washing process. KP washing process is consist of multiple washing equipment, and Fig. 1 shows an example flow.

As indicate in this figure, the first washing equipment "(1) Hi-heat washing zone" is located at the bottom of the main KP cooking digester, and cooked pulp stocks that are descending with blackening cooking liquid chemicals (black liquor) in the digester are washed and stop the cooking reaction of pulp stocks by the washing water (dilute black liquor) rising upward with countercurrent flow that are injected from bottom of the digester. And they are taking out to outside as black liquors, along with washing water from center area of the digester to recover the dissolved lignin components and chemical compounds.

Though different flows that is suitable for the each mill's actual situation are taken in actual, Fig. 1 shows an example configuration follows by (1), that consist of six washing equipments in total. Those are "(2) Pressurized diffusion washer (PDW)", "(3) Diffusion washer (DW)", "(4) Washing filter" before the oxygen $\left(\mathrm{O}_{2}\right)$ bleaching process, "(5) Double pressure filter (DP washer)" after the $\mathrm{O}_{2}$ bleaching process and "6) Bleach pre washing filter" before the final ECF bleaching process. (2) PDW and (3) DW are the washing equipments that consist of special mechanical structures, and they wash away the dark brown black liquors and lignin components very firmly that are attached to the blow pulp stocks strongly extracted from the bottom of KP digester. And the washing filtrates generated by (3) DW are reused for the washing water of (2) PDW, and the washing filtrate generated by (2) PDW are reused for the washing water of (1) Hi-heat washing zone of KP cooking digester again, effectively.

Furthermore, in the oxygen $\left(\mathrm{O}_{2}\right)$ bleaching process that is situated between (4) Washing filter and (5) DP washer, "Oxidized white liquor (main ingredient: $\mathrm{H}_{2} \mathrm{SO}_{4}$, $\mathrm{NaOH}$ etc.) " of alkali chemicals is added again to the pulp stocks to improve the delignification reaction of the pulp stocks. Therefore, after the $\mathrm{O}_{2}$ bleaching process, the brown pulp stocks are washed, once again by (5) DP washer. And at the same time, the expensive residual chemical compounds after the $\mathrm{O}_{2}$ bleaching process have

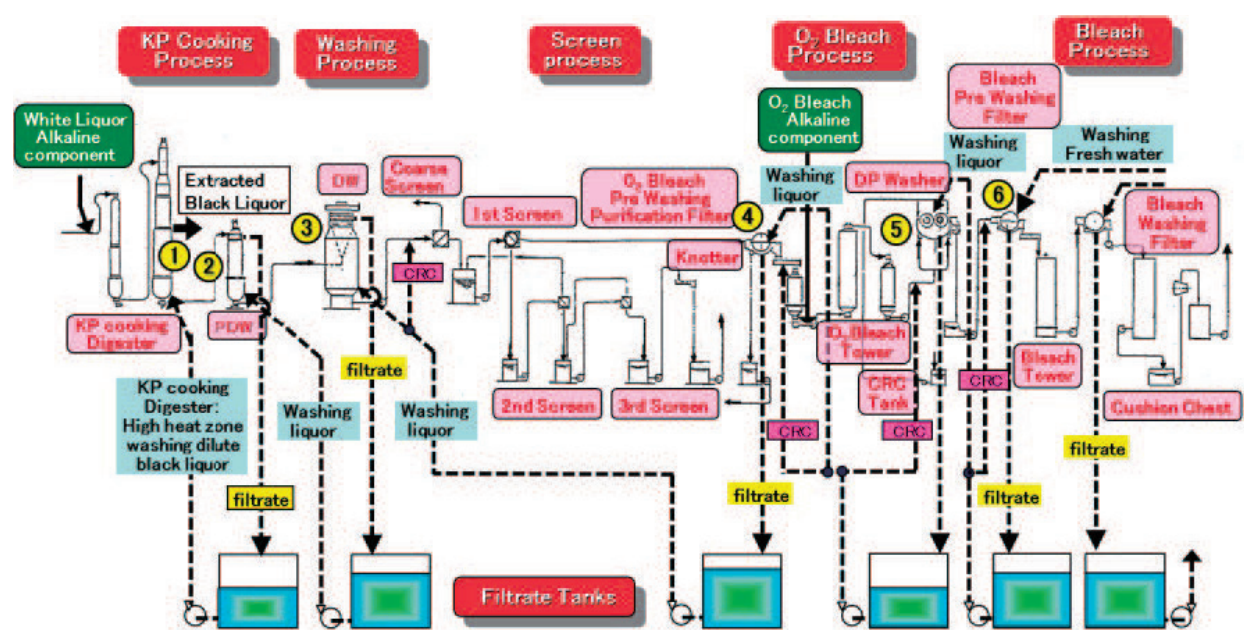

Fig. 1 Kraft pulp production and washing process flow. 
to be recovered from the washing filtrates of (5).

Also, pulp bleaching is done by ECF bleaching flow at the last KP process, and as the pretreatment, chemical compounds that remain in the pulp stocks are washed by (6) Bleach pre-washing filter. It should be noted that not only to wash and remove the residual chemicals and lignin components, but also to separate and remove the small foreign matters (undigested pulp knot components, pulp lumps, bark of wood, and dirt etc.) I n this washing process, at the same time, and this operation is called "screening process".

\subsection{KP chemicals' recovery process and regenera- tion cycle}

Fig. 2 shows the circulation flow of the chemical compounds of KP process. The black liquor that taken out from the upper end of (1) Hi-heat washing zone of $\mathrm{KP}$ cooking digester, along with the washing finished filtrates, contain amount of inflammable lignin components that were dissolved from wood chips by KP cooking reaction along with the sodium $(\mathrm{Na})$ compounds of the cooking chemicals (they are called as alkali compounds, also). After the diluted black liquors were extracted with the consistency of about $20 \%$ from KP cooking digester, they are concentrated to about $70 \%$ high consistency by the following Evaporator equipment. Then, they are burned by the Sodium-Recovery Boiler, and generate high pressure steam and electric power, and they are using in KP mill processes. At the same time, the melting $\mathrm{Na}$ compounds, called "smelt", that are discharged from the bottom of the Recovery Boiler are sent to following KP causticizing process. Those chemical compounds are recovered through the caustic reaction of the regenerate cycle, and almost all amount of the white liquor chemicals for KP cooking are recovered and regenerated.

Therefore, KP washing process is required to wash

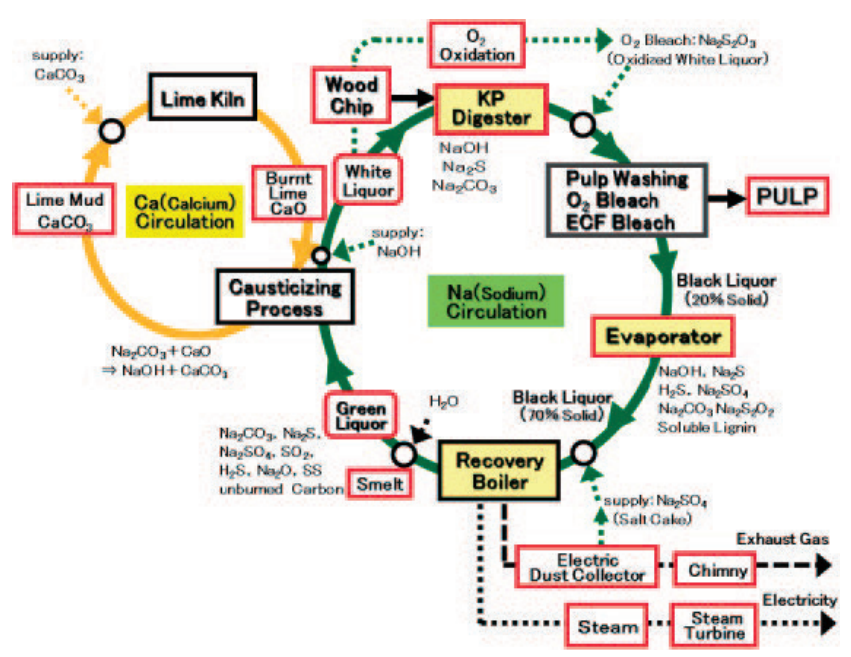

Fig. 2 Kraft pulp chemical circulation flow overview.
KP pulp stocks efficiently to recover the expensive chemical compounds, such as sodium ( $\mathrm{Na}$ ) etc., in the washing filtrates, that contained in KP cooking chemicals (white liquor) with a small amount of washing water, so as to save water, and to recover washed filtrates with high concentration states, as much as possible, not to waste the steam energy to evaporate the recovered black liquors in the Recovery Boiler equipment of the preprocessing of chemical recovery process.

\section{Brown stock washing}

3.1 Displacement washing and washing filter

It is known some washing methods ${ }^{1}$, for example, (a) Dilute dewatering washing, (b) Press washing, and (c) Displacement washing and so on.

(a) Dilute dewatering washing is follows. After diluting the dissolved materials well by adding enough clean washing water to the washing materials, and washing is done by the dewatering filtration using filter equipment. (b) Press washing is done by mechanical compression and pressurized dewatering, such as roll-press type washing equipment, for example.

In (c) Displacement washing, materials (pulp stocks) are washed by the displacement operation. After the pulp stocks are diluted properly, make pulp mats on the washing filter drum by the filtrate operation, the water showers are washed away and replace the chemical components that are dissolved and impregnated in the pulp mat and solid components with the shower water, by pressurized shower water blown onto the filter drum strongly and directly from the shower nozzles. Fig. 3 shows the concept of the "displacement washing". The pulp washing equipments discussed in this paper are almost all use this type of equipment.

For the pulp stock washing, it is used a drum type washing filter $(\approx \phi 3.5 \mathrm{~m}$ diameter $\times \approx 8 \mathrm{~m}$ width) well, such as Fig. 4. The displacement washing is utilized to wash a large amount of attached chemical components (Na) that are dissolved and impregnated from pulp stocks. Shooting the pulp mats on the rotating filter

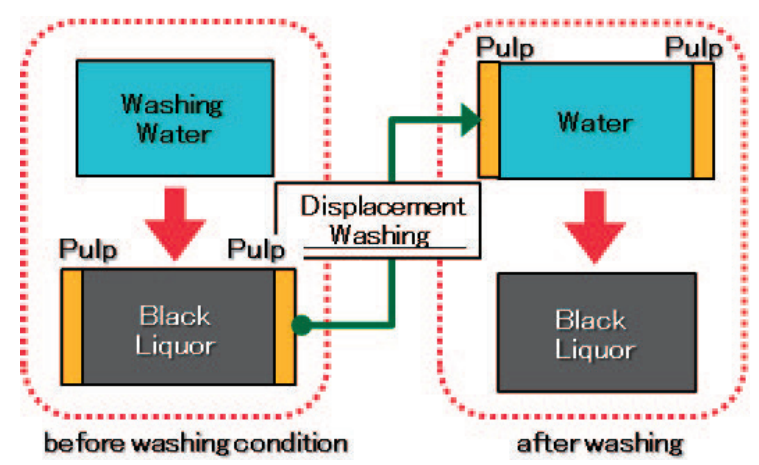

Fig. 3 Displacement washing. 


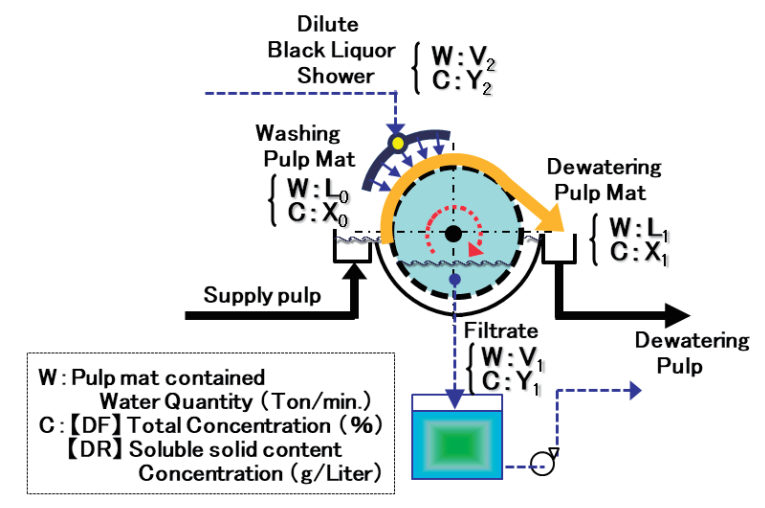

$\mathrm{L}_{0}$ : Water Quantity brought in with unwashed pulp stock $\left(\mathrm{m}^{3} / \mathrm{min}\right.$.)

$\mathrm{V}_{2}$ : Quantity of Wash water $\left(\mathrm{m}^{3} / \mathrm{min}\right.$.)

$\mathrm{V}_{1}$ : Recovered Quantity of Filtrate $\left(\mathrm{m}^{3} / \mathrm{min}\right.$.)

$\mathrm{L}_{1}$ : Water Quantity brought out with washed pulp mat $\left(\mathrm{m}^{3} / \mathrm{min}\right.$.)

- In case of DF (Dilution Factor)

$\overline{\mathrm{X}_{0}}$ : Total consistency of unwashed pulp stock (\%)

$\mathrm{Y}_{2}$ : Total consistency of wash water $(\%)$

$\mathrm{X}_{1}$ : Total consistency of washed pulp mat $(\%)$

$\mathrm{Y}_{1}$ : Total consistency of recovered filtrate $(\%)$

- In case of DR (Displacement Ratio)

$\mathrm{X}_{\mathrm{O}}$ : Soluble solid conc. contained with unwashed pulp stock (g/Liter)

$\mathrm{Y}_{2}$ : Soluble solid conc. contained with wash water (g/Liter)

$\mathrm{X}_{1}$ : Soluble solid conc. contained with washed pulp mat ( $\mathrm{g} /$ Liter)

$\mathrm{Y}_{1}$ : Soluble solid conc. of recovered filtrate ( $\mathrm{g} /$ Liter)

Fig. 4 Washing filter and soluble solid.

drum by high pressurized clean shower water, and sucking the pulp mats by low vacuum that are generated by the filtrate line and filtrate streams of the leg pipes.

As a result, the chemical components that were removed from pulp stocks are accumulated in the filtrates of the washing filter, and, some chemical components are remained in the pulp stocks that could not remove completely by the washing filter.

\subsection{Washing management: Dilution factor (DF value)}

For the pulp stock washing process management, “DF: Dilution Factor" value is used widely. The DF value is defined by the following Eq. (1).

The value is calculated in terms of per unit of production, and the value subtracting the water quantity: $\mathrm{L}_{1}$ that carried away accompanied with the pulp stocks after washing, from the washing water quantity: $V_{2}$ that were supplied to the washing equipment based on the supplying stock pulp weight: $\mathrm{W}_{\mathrm{ADT}}(\mathrm{ADT} / \mathrm{min}$.) to the washing equipment (referring to Fig. 4$)^{2) \sim 5 \text { ) }}$.

Though this DF value is operated around from 1 to 3 , in general, it is possible to be negative (minus) values depending on the operating conditions. On the contrary, in the actual plant, it is difficult to measure and to know the value of the water quantity: $\mathrm{L}_{1}$ exactly that carried away accompanied with pulp stocks, and the value of the denominator: $\mathrm{W}_{\mathrm{ADT}}$ in the washing process online. There- fore, when we calculate Eq. (1). have to approximate as a fixed value for washed and dewatering pulp mat consistency and so on (for example 10\%, 15\% etc.).

$$
\mathrm{DF}=\frac{\mathrm{V}_{2}-\mathrm{L}_{1}}{\mathrm{~W}_{\mathrm{ADT}}}
$$

\subsection{Washing indicator: Displacement ratio(DR value)}

Next, review the evaluation method about the washing states of pulp stocks. It has been proposed various evaluation methods for the value, that representing the washing efficiency of chemicals and solid components that are removed from the pulp stocks in the washing operations. As the typical index value for the washing states, "DR: Displacement Ratio" is the most famous. There is an evaluation methods that indicate in Eq. (2), that focused on the changes of the solid component amounts that are contained in the pulp mats. And another method is Eq. (3), that finally focused on the states of the solid components' consistency changes.

In addition to that, EDR method (Equivalent Displacement Ratio), Norden efficiency coefficient method (1966) and several others are proposed ${ }^{3) 5)}$. But every index values are required to calculate based on the actual measured values of the washing equipment.

$$
\begin{aligned}
\operatorname{DR}(\%) & =\left\{\frac{\left(\mathrm{L}_{0} \cdot \mathrm{X}_{0}\right)-\left(\mathrm{L}_{1} \cdot \mathrm{X}_{1}\right)}{\left(\mathrm{L}_{0} \cdot \mathrm{X}_{0}\right)-\left(\mathrm{V}_{2} \cdot \mathrm{Y}_{2}\right)}\right\} \cdot 100 \\
\text { or } & \\
\operatorname{DR}(\%) & =\left\{\frac{\mathrm{X}_{0}-\mathrm{X}_{1}}{\mathrm{X}_{0}-\mathrm{Y}_{2}}\right\} \cdot 100
\end{aligned}
$$

The displacement ratio Eq. (3) is an evaluation method, that proposed by Perkins, J. H. et al. ${ }^{2}$ in 1954, and this value is used widely in the actual operations. In the case of washing equipment of Fig. 4, the DR value can evaluate the washing efficiency of the "displacement washing".

This value is calculated based on the ratio, with the value subtracting the chemical consistency: $\mathrm{Y}_{2}$ that contained in the washing waters from the chemical consistency: $\mathrm{X}_{0}$ that contained in the pulp mats before washing, and the value subtracting the chemical consistency: $\mathrm{X}_{1}$ that retained in the pulp mats after washing from the value: $\mathrm{X}_{0}$ as mentioned before.

Here, I consider about the index value of "washing displacement ratio: DR”, just a little more. For example, in the drum type washing filter with shower washing equipments, as shown in Fig. 4, it satisfied the flow conservation equation (Eq. (4)) and the chemical component weight equation (Eq. (5)) shown to the following simultaneous equations, always. 


$$
\begin{gathered}
\left\{\begin{array}{l}
\mathrm{L}_{1}+\mathrm{V}_{1}=\mathrm{L}_{0}+\mathrm{V}_{2} \\
\mathrm{~L}_{1} \cdot \mathrm{X}_{1}+\mathrm{V}_{1} \cdot \mathrm{Y}_{1}=\mathrm{L}_{0} \cdot \mathrm{X}_{0}+\mathrm{V}_{2} \cdot \mathrm{Y}_{2}
\end{array}\right. \\
\Rightarrow \mathrm{L}_{0}=\mathrm{L}_{1}+\mathrm{V}_{1}-\mathrm{V}_{2}
\end{gathered}
$$

If the "displacement washing" described in Fig. 3 is performed perfectly in this washing equipment, the washing quantity of the pulp mat: $V_{2}$ is, on this theory, equal to the washing quantity: $\mathrm{L}_{1}$, at maximum, and the value of both flows ratio: $\left(\mathrm{V}_{2} / \mathrm{L}_{1}\right) \times 100(\%)$ in the actual equipment is regarded as washing achievement ratio. Therefore, it will be able to admit, the value of "displacement ratio" could evaluate the washing efficiency.

Here, move the variable $\mathrm{L}_{0}$ to the left, in Eq. (4), and deform the formula as Eq. (6). Next, substituting it into Eq. (5), and erases the variable $\mathrm{L}_{0}$. Furthermore, proceeding the deformation the formula by paying attention to the previous term of flow ratio: $\left(\mathrm{V}_{2} / \mathrm{L}_{1}\right)$, we can derive the following Eq. (7) relationship. Then, the same term of Eq. (3) that defines the DR value appears in the left-hand side of the equation.

On the other hand, there are following relationships of $\left(\mathrm{X}_{0}-\mathrm{Y}_{1}\right)>0,\left(\mathrm{X}_{0}-\mathrm{Y}_{2}\right)>0$ and $\left(\mathrm{V}_{1} / \mathrm{L}_{1}\right) \geqq 0$, between the consistencies of each chemical components that are contained in the supplying pulp stocks, shower washing waters and the washing filtrates: $\mathrm{X}_{0}, \mathrm{Y}_{2}, \mathrm{Y}_{1}$, in general. Finally, the following Eq. (7)'s relationship of inequality can be derived, and we can admit the definition of the washing replacement ratio: DR value of Eq. (3).

$$
\begin{aligned}
\left\{\frac{\mathrm{X}_{0}-\mathrm{X}_{1}}{\mathrm{X}_{0}-\mathrm{Y}_{2}}\right\} & =\left\{\left(\frac{\mathrm{V}_{2}}{\mathrm{~L}_{1}}\right)-\left(\frac{\mathrm{V}_{1}}{\mathrm{~L}_{1}}\right) \cdot \frac{\left(\mathrm{X}_{0}-\mathrm{Y}_{1}\right)}{\left(\mathrm{X}_{0}-\mathrm{Y}_{2}\right)}\right\} \\
\leq\left\{\frac{\mathrm{V}_{2}}{\mathrm{~L}_{1}}\right\} & \approx \frac{\mathrm{DR}(\%)}{100}
\end{aligned}
$$

$$
\left(\mathrm{V}_{1} / \mathrm{L}_{1}\right) \geq 0,\left(\mathrm{X}_{0}-\mathrm{Y}_{1}\right)>0,\left(\mathrm{X}_{0}-\mathrm{Y}_{2}\right)>0
$$
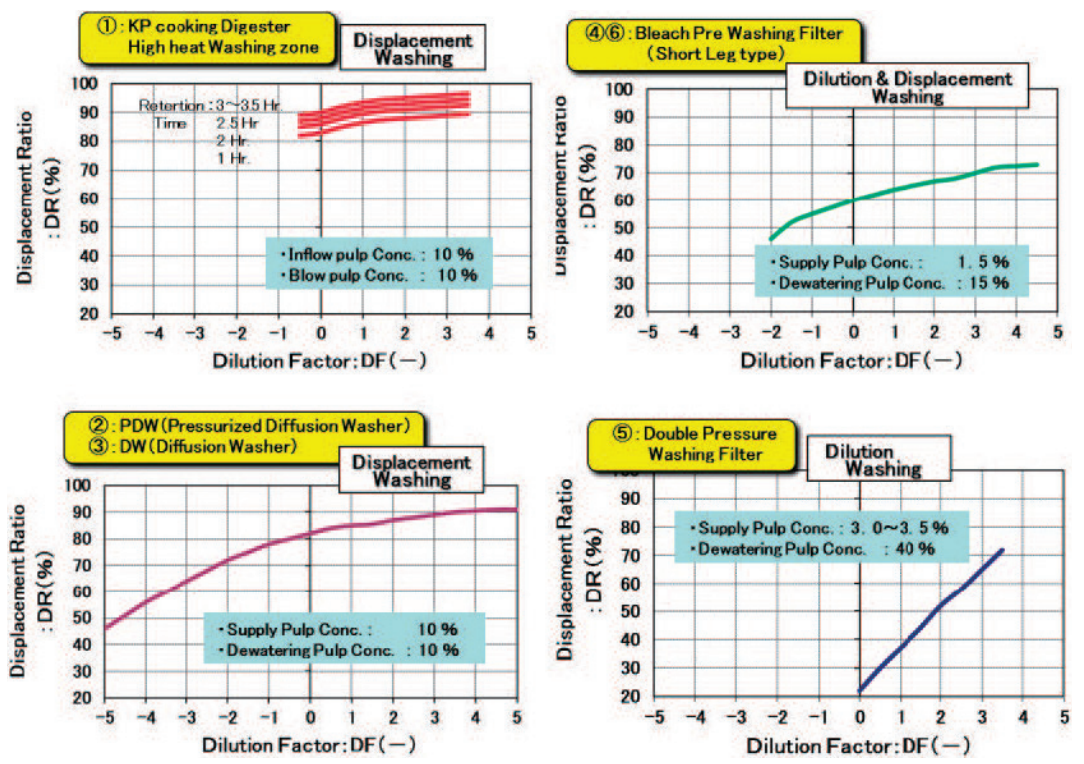

Fig. 5 Dilution factor (DF) vs. Displacement ratio (DR) of pulp washing equipments.
The value of “displacement washing ratio: DR" of Eq. $(3)(=$ Eq. $(7))$, becomes DR $=100 \%$, if the whole washing shower flow are replaced to the water contents of the pulp stocks by the "Displacement washing", because the dissolving consistencies of the chemical components are $\mathrm{X}_{1}=\mathrm{Y}_{2}$. However, the achievement-ratio of the displacement washing values become about DR $=50 \sim$ $90 \%$ in the actual washing equipments, as shown in the next section.

\section{About KP washing process operation}

4.1 Relation between DF value and DR value

Fig. 5 shows some example relation graphs between the "dilution Factor (DF)" and the "displacement washing ratio (DR)” based on Eq. (3).

The horizontal axis indicates the DR value, and the vertical axis indicate the DF value in every graph. The graph of the upper left is (1) Hi-heat washing zone of $\mathrm{KP}$ cooking digester, the lower left is (2) PDW, (3) DW, and the graph of the upper right is (4) Washing filter and (6) Bleach pre washing filter, and the graph of the lower right is (5) DP washer. However, it is required to examine through the actual measurement for each equipments, because we cannot avoid some malfunctions of each equipment, the fluctuations and changes during over times, besides each washing equipment shows individual specific performances. Furthermore, the value of DR of (1) Hi-heat washing zone of KP cooking digester varies under the influence of the changes of the operation set value of the dilution factor: DF, and the variation of the retention time in the washing zone, according to the change of the pulp production, also. 
4.2 Cross flow washing and countercurrent flow washing

We can consider various pulp washing flow lines for the actual plant ${ }^{1}$.

The simplest washing flow is the "Cross flow washing", that wash the pulp stocks individually with clean fresh water only, against all individual equipment, successively. The conceptual diagram shows in Fig. 6 (A).

However, it required a large amount of washing water in this "cross flow washing" method. Furthermore, besides the amount of the washing filtrates (waste water) are so large, the consistency of the dirty waste water that are generated in the washing process are fairly diluted. Therefore, another problem occurs in the post processing process for the waste water.

To prevent this problem the "Countercurrent flow washing" method, shown in Fig. 6 (B), has been used for a long time, for KP plant of the pulp washing process.

In the "Countercurrent flow washing", the clean washing water were supplied only to the final point of the washing process, and the washing filtrates that are dis-

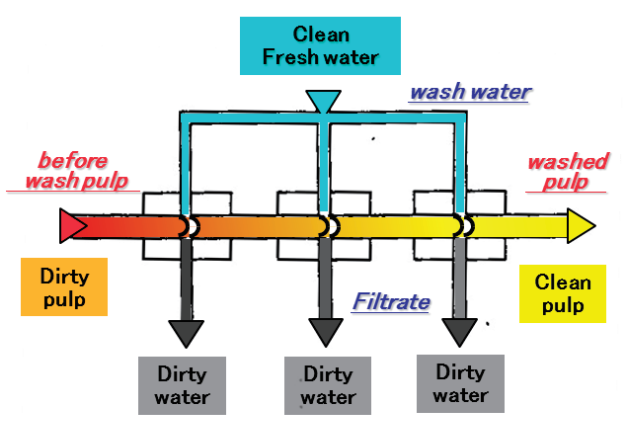

(A) Cross flow washing

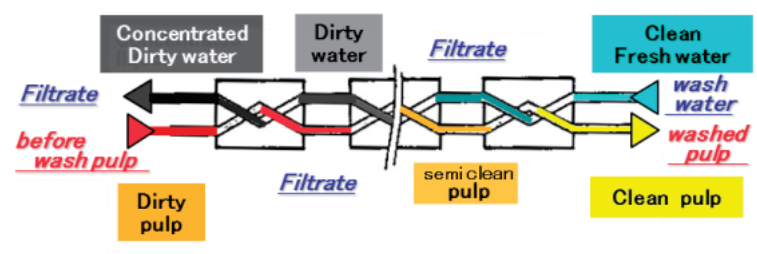

(B) Countercurrent flow washing

Fig. 6 Two types of washing flow ${ }^{1)}$. charged from the washing equipment are re-using the filtrates for the washing water of the one previous washing equipment, so on. In other words, the washing method is to repeat re-using the filtrates as wash water of the one previous stage's washing equipment, and the flow direction of the washing water and the pulp stocks are quite opposite. Finally, the filtrates are not large amount but waste components are dissolved and concentrated to considerably high consistency, and taken out to outside, from one extraction line of the most beginning point of the washing process. In this case, the filtrates are used repeatedly for washing water with the "displacement washing", and the chemical components consistencies in the filtrate increase steadily and the contamination of the washing water become worsen gradually. However, the cleaning states of the pulp stocks are not worsened and it will be cleaned gradually, because the washing operations are done usually using the filtrates that are less contaminated washing water compared to the targeted pulp stocks, always. In the next chapter, we will consider about the modeling of the washing processes.

\section{Modelling for KP washing process}

\subsection{Countercurrent flow washing}

5.1.1 Modelling for countercurrent flow washing

Fig. 7 shows the model diagram that were used the graph expression for Fig. 1: “(B) countercurrent flow washing” in KP washing process. In this graph expression model, the washing equipment and washing filtrate tanks are indicated by circled Nodes, and the number from No.1 to 15 to each node are assigned. And, it is noted that the "Source node" is No.0 and the "Sink node" is No.16. Furthermore, in the figure, the pulp stock flows are indicated by the Arcs (arrows) of solid lines, and the washing water and the filtrate flows are indicated by the Arcs (arrows) of dashed line, and chemicals that contain alkali $(\mathrm{Na})$ components that added to the process and the washing clean water from outside, are indicated by the Arcs of dashed lines.

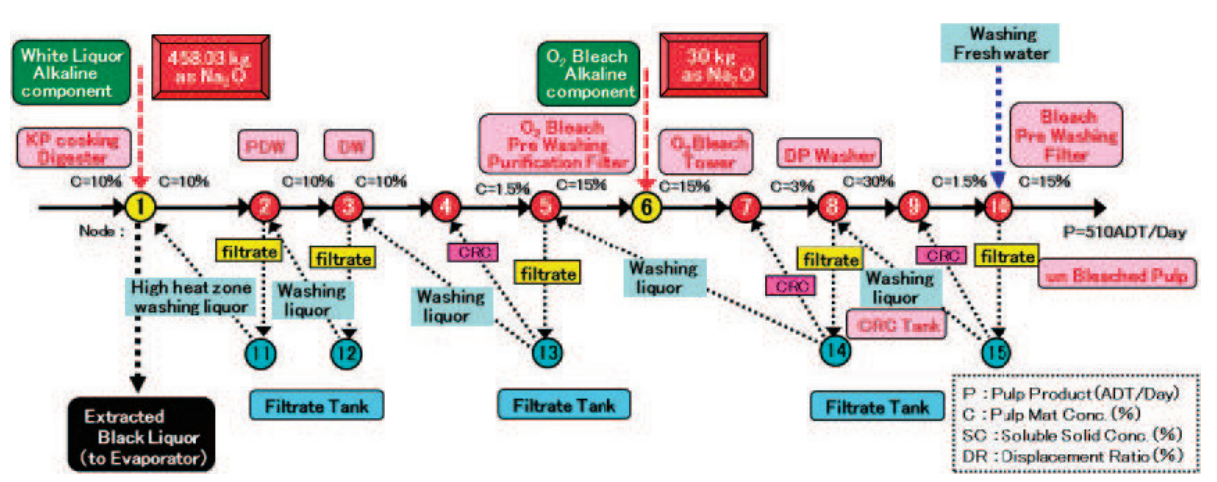

Fig. 7 Stock washing process model for a countercurrent flow. 
Table 1 Quantity of arc flow for stock washing model.

\begin{tabular}{|c|c|c|c|}
\hline \multirow{2}{*}{$\begin{array}{c}\text { Arc flow } \\
\text { Name. }\end{array}$} & \multicolumn{2}{|c|}{ Arc No. } & \multirow{2}{*}{ Quantity of flow ( $\mathrm{m}^{3} / \mathrm{min}$.) } \\
\hline & From & To & \\
\hline Q1 & $\mathbf{0}$ & 1 & $0.9 \cdot \mathrm{P} \cdot(1-\mathrm{PC} 1) /(1,440 \cdot \mathrm{PC} 1)$ \\
\hline Q2 & 0 & 6 & 0 \\
\hline Q3 & 0 & 10 & $\{0.9 \cdot P \cdot(1-P C 27) /(P C 27 \cdot 1440)\}+\{(D F 10) \cdot P / 1,440\}$ \\
\hline Q4 & 1 & 2 & $0.9 \cdot \mathrm{P} \cdot(1-\mathrm{PC} 4) /(1,440 \cdot \mathrm{PC} 4)$ \\
\hline Q5 & 2 & 3 & $0.9 \cdot P \cdot(1-P C 5) /(1,440 \cdot P C 5)$ \\
\hline Q6 & 3 & 4 & $0.9 \cdot P \cdot(1-P C 6) /(1,440 \cdot P C 6)$ \\
\hline Q7 & 4 & 5 & $0.9 \cdot P \cdot(1-P C 7) /(1,440 \cdot P C 7)$ \\
\hline Q8 & 5 & 6 & $0.9 \cdot P \cdot(1-P C 8) /(1,440 \cdot P C 8)$ \\
\hline Q9 & 6 & 7 & Q10-Q21 \\
\hline Q10 & 7 & 8 & $0.9 \cdot \mathrm{P} \cdot(1-\mathrm{PC} 10) /(1,440 \cdot \mathrm{PC} 10)$ \\
\hline Q11 & 8 & 9 & $0.9 \cdot P \cdot(1-P C 11) /(1,440 \cdot P C 11)$ \\
\hline Q12 & 9 & 10 & $0.9 \cdot \mathrm{P} \cdot(1-\mathrm{PC} 12) /(1,440 \cdot \mathrm{PC} 12)$ \\
\hline Q13 & 11 & 1 & $\{0.9 \cdot P \cdot(1-P C 4) /(1,440 \cdot P C 4)\}+\{(D F 1) \cdot P / 1,440\}$ \\
\hline Q14 & 2 & 11 & Q4+Q15-Q5 \\
\hline Q15 & 12 & 2 & $\{0.9 \cdot P \cdot(1-P C 5) /(1,440 \cdot P C 5)\}+\{(D F 2) \cdot P / 1,440\}$ \\
\hline Q16 & 3 & 12 & Q5+Q17-Q6 \\
\hline Q17 & 13 & 3 & $\{0.9 \cdot P \cdot(1-P C 6) /(1,440 \cdot P C 6)\}+\{(D F 3) \cdot P / 1,440\}$ \\
\hline Q18 & 13 & 4 & Q7-Q6 \\
\hline Q19 & 5 & 13 & Q7+Q20-Q8 \\
\hline Q20 & 14 & 5 & $\{0.9 \cdot P \cdot(1-P C 8) /(1,440 \cdot P C 8)\}+\{(D F 5) \cdot P / 1,440\}$ \\
\hline Q21 & 14 & 7 & Q22-Q20 \\
\hline Q22 & 8 & 14 & Q10+Q23-Q11 \\
\hline Q23 & 15 & 8 & {$[0.9 \cdot P \cdot(1-P C 11) /(1,440 \cdot P C 11)\}+\{(D F 8) \cdot P / 1,440\}$} \\
\hline Q24 & 15 & 9 & Q12-Q11 \\
\hline Q25 & 10 & 15 & Q3+Q12-Q27 \\
\hline Q27 & 1 & 16 & Q1+Q13-Q4 \\
\hline Q28 & 10 & 16 & $0.9 \cdot \mathrm{P} \cdot(1-\mathrm{PC} 27) /(1,440 \cdot \mathrm{PC} 27)$ \\
\hline
\end{tabular}

Table 2 Equation at each Nodes for stock washing model.

\begin{tabular}{|c|c|c|c|}
\hline Group & Eq. No. & Node No. & Equation \\
\hline \multirow{6}{*}{$\begin{array}{c}\text { (i ) Wash Water } \\
\text { Quantity } \\
\text { Equation } \\
\text { based on DR }\end{array}$} & 1 & 1 & 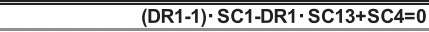 \\
\hline & 2 & 2 & $(\mathrm{DR} 2-1) \cdot \mathrm{SC} 4-\mathrm{DR} 2 \cdot \mathrm{SC} 15+\mathrm{SC} 5=0$ \\
\hline & 3 & 3 & (DR3-1) $\cdot$ SC5-DR3 $\cdot$ SC17+SC6 $=0$ \\
\hline & 4 & 5 & $(\mathrm{DR} 5-1) \cdot \mathrm{SC} 7-\mathrm{DR} 5 \cdot \mathrm{SC} 20+\mathrm{SC} 8=0$ \\
\hline & 5 & 8 & (DR8-1) - SC10-DR8-SC23+SC11 $=0$ \\
\hline & 6 & 10 & $(\mathrm{DR} 10-1) \cdot \mathrm{SC} 12-\mathrm{DR} 10 \cdot \mathrm{SC} 3+\mathrm{SC} 27=0$ \\
\hline \multirow{8}{*}{$\begin{array}{l}\text { (ii) Soluble } \\
\text { Alkaline Solid } \\
\text { Concentration } \\
\text { Equation }\end{array}$} & 7 & 1 & SC13-SC14=0 \\
\hline & 8 & 2 & SC15-SC16 $=0$ \\
\hline & 9 & 3 & SC17-SC18 $=0$ \\
\hline & 10 & 4 & SC18-SC19=0 \\
\hline & 11 & 5 & $S C 20-S C 21=0$ \\
\hline & 12 & 6 & $\mathrm{SC21}-\mathrm{SC22}=0$ \\
\hline & 13 & 7 & SC23-SC24=0 \\
\hline & 14 & 8 & $\mathrm{SC24-SC25=0}$ \\
\hline \multirow{15}{*}{$\begin{array}{l}\text { (iii) Alkaline } \\
\text { contain Amount } \\
\text { Equation }\end{array}$} & 15 & 1 & $Q 1 \cdot S C 1+Q 13 \cdot S C 13-Q 4 \cdot S C 4-Q 26 \cdot S C 26=0$ \\
\hline & 16 & 2 & Q4.SC4+Q15.SC15-Q14.SC14-Q5.SC5 $=0$ \\
\hline & 17 & 3 & $Q 5 \cdot S C 5+Q 17 \cdot S C 17-Q 6 \cdot S C 6-Q 16 \cdot S C 16=0$ \\
\hline & 18 & 4 & $\mathrm{Q6} \cdot \mathrm{SC} 6+\mathrm{Q} 18 \cdot \mathrm{SC} 18-\mathrm{Q} 7 \cdot \mathrm{SC} 7=0$ \\
\hline & 19 & 5 & $Q 7 \cdot S C 7+Q 20 \cdot S C 20-Q 8 \cdot S C 8-Q 19 \cdot S C 19=0$ \\
\hline & 20 & 6 & Q8 $\cdot$ SC8+AAA2-Q9 $\cdot S C 9=0$ \\
\hline & 21 & 7 & $Q 9 \cdot S C 9+Q 21 \cdot S C 21-Q 10 \cdot S C 10=0$ \\
\hline & 22 & 8 & $Q 10 \cdot S C 10+Q 23 \cdot S C 23-Q 22 \cdot S C 22-Q 11 \cdot S C 11=0$ \\
\hline & 23 & 9 & $Q 11 \cdot S C 11+Q 24 \cdot S C 24-Q 12 \cdot S C 12=0$ \\
\hline & 24 & 10 & $\mathrm{Q} 12 \cdot \mathrm{SC} 12+\mathrm{Q} 3 \cdot \mathrm{SC} 3-\mathrm{Q} 25 \cdot \mathrm{SC} 25-\mathrm{Q} 27 \cdot \mathrm{SC} 27=0$ \\
\hline & 25 & 11 & $(Q 13-Q 14) \cdot S C 13=0$ \\
\hline & 26 & 12 & $(Q 15-Q 16) \cdot S C 15=0$ \\
\hline & 27 & 13 & $(Q 19-Q 17-Q 18) \cdot S C 19=0$ \\
\hline & 28 & 14 & $(Q 22-Q 20-Q 21) \cdot S C 22=0$ \\
\hline & 29 & 15 & $(Q 25-Q 23-Q 24) \cdot S C 25=0$ \\
\hline
\end{tabular}

Table 1, 2, 3 shows the detail setting information in this graph. The first Table 1 shows each flow-rate between two nodes that are connected according to the arc flows of the graph of Fig. 7. And, in this flow calculation, it is required to know the values of the water weight that contained in the brown pulp stocks: $\mathrm{W}_{\text {water }}$. This value can be calculated by the following Eq. (8), that was transformed based on the relation between the production rate of the unbleached pulp production: $\mathrm{P}$ (ADT/ Day) and the pulp consistency: PC $(\% \times 1 / 100)$, approximately. And the term is appeared in Table 1 here and
Table 3 Setting conditions for stock washing simulation.

\begin{tabular}{|c|c|c|c|c|}
\hline ITEMs & $\begin{array}{c}\text { Variable } \\
\text { Name }\end{array}$ & Calc. Equation. & Unit & Value \\
\hline Pulp production: & $P$ & & ADT/Day & 510 \\
\hline $\begin{array}{l}\text { - KP Digester High heat } \\
\text { Washing zone In Pulp Conc.: }\end{array}$ & PC1 & & $\%$ & 10 \\
\hline -PDW In Pulp Conc.: & PC4 & & $\%$ & 10 \\
\hline - DW In Pulp Conc.: & PC5 & & $\%$ & 10 \\
\hline . " Out Pulp Conc.: & PC6 & & $\%$ & 10 \\
\hline $\begin{array}{l}\mathrm{O}_{2} \text { Bleach pre Washing Filter } \\
\text { In Pulp Conc.: }\end{array}$ & PC7 & & $\%$ & 1.5 \\
\hline . " $\quad$ Out Pulp Conc.: & PC8 & & $\%$ & 15 \\
\hline -DP Washer In Pulp Conc.: & PC10 & & $\%$ & 3 \\
\hline . " Out Pulp Conc.: & PC11 & & $\%$ & 30 \\
\hline $\begin{array}{l}\text { - Bleach pre Washing Filter } \\
\text { In Pulp Conc.: }\end{array}$ & PC12 & & $\%$ & 1.5 \\
\hline - " Out Pulp Conc.: & $\mathrm{PC27}$ & & $\%$ & 15 \\
\hline - Bleach Pulp Yield: & BS & & $(1 / 100) \cdot \%$ & 0.95 \\
\hline - UnBleached Pulp Yield: & PS & & $(1 / 100) \cdot \%$ & 0.44 \\
\hline $\begin{array}{l}\text {-White Liquor dosage: } \\
\text { (vs. Wood chip weight } \\
\text { as Active Alkaline) }\end{array}$ & AADR & & $(1 / 100) \cdot \%$ & 0.18 \\
\hline -Active Alkaline Conc.: & AACN & & g/Liter & 110 \\
\hline -Total Alkaline Conc.: & TACN & & g/Liter & 130 \\
\hline $\begin{array}{l}\text {-KP Digester Alkaline } \\
\text { Additive Quant.: }\end{array}$ & AAA1 & $\frac{900 \cdot \text { AADR } \cdot \text { TACN }}{\text { BS } \cdot \text { PS } \cdot \text { AACN }}$ & $\begin{array}{c}\mathrm{kg} / \mathrm{ADT} \\
\left.\text { (as } \mathrm{Na}_{2} \mathrm{O}\right)\end{array}$ & 458.03 \\
\hline $\begin{array}{l}\text {-Alkaline Conc. entering to } \\
\text { KP Digester } \\
\text { High heat washing zone: }\end{array}$ & sc1 & $\frac{\text { AAA1 } \cdot P}{24 \cdot 60 \cdot Q 1}$ & $\%$ & 55.94 \\
\hline -Wash Fresh water Conc.: & SC3 & & $\%$ & 0 \\
\hline - $\mathrm{O}_{2}$ Bleach Alkaline Dosage: & AA2 & & $\begin{array}{l}\mathrm{kg} / \mathrm{ADT} \\
\left(\text { as } \mathrm{Na}_{2} \mathrm{O}\right)\end{array}$ & 30 \\
\hline $\begin{array}{l}\cdot \mathrm{O}_{2} \text { Bleach Alkaline } \\
\text { Additive Quant.: }\end{array}$ & AAA2 & $\frac{\mathrm{AA2} \cdot \mathrm{P}}{24 \cdot 60}$ & $\begin{array}{l}\mathrm{kg} / \mathrm{min} \\
\left(\text { as } \mathrm{Na}_{2} \mathrm{O}\right)\end{array}$ & 10.125 \\
\hline $\begin{array}{l}\text { KP Digseter High heat } \\
\text { Washing zone DR-value : }\end{array}$ & DR1 & & - $10-2-7$ & 0.935 \\
\hline . & DF1 & & - & 2.5 \\
\hline ·PDW DR-value: & DR2 & & - & 0.87 \\
\hline - "I DF-value: & DF2 & & - & 2.5 \\
\hline -DW DR-value: & DR3 & & - & 0.87 \\
\hline$\cdot \|$ DF-value: & $\mathrm{DF} 3$ & & - & 2.5 \\
\hline $\begin{array}{l}\text { - } \mathrm{O}_{2} \text { Bleach pre Washing Filter } \\
\text { DR-value: }\end{array}$ & DR5 & & - & 0.75 \\
\hline · II DF-value: & DF5 & & - & 2.5 \\
\hline - DP Washer DR-value : & DR8 & & - & 0.52 \\
\hline . $\quad \prime \prime \prime$ DF-value: & DF8 & & - & 2.5 \\
\hline $\begin{array}{l}\text { - Bleach pre Washing Filter } \\
\text { DR-value : }\end{array}$ & DR10 & & - & 0.65 \\
\hline . $\quad \prime \prime \prime$ DF-value: & DF10 & & - & 2.5 \\
\hline - unknown Arc Quantity: & Q1 Q27 & & $\mathrm{m}^{3 / m i n}$. & unknown \\
\hline
\end{tabular}

there. Here, the conversion of pulp weight from ADT (air dried weight) to BDT (bone dried weight), that is required at the pulp weight calculation, was done by multiplying the coefficient value of 0.9 , according to the conventional method, assuming that the moisture content of air dried pulp is $10 \%$.

$$
\begin{aligned}
\mathrm{PC} & =\frac{\mathrm{W}_{\text {pulp }}}{\mathrm{W}_{\text {pulp }}+\mathrm{W}_{\text {water }}} \\
& =\frac{\{(0.9 \times \mathrm{P} /(24 \mathrm{Hr} . / \mathrm{D} \times 60 \mathrm{~min} / \mathrm{Hr} .))\}}{\{(0.9 \times \mathrm{P} /(24 \mathrm{Hr} . / \mathrm{D} \times 60 \mathrm{~min} / \mathrm{Hr} .))\}+\mathrm{W}_{\text {water }}} \\
& \Rightarrow \quad \mathrm{W}_{\text {water }}=0.9 \times \mathrm{P} \times\left\{\frac{1-\mathrm{PC}}{1,440 \times \mathrm{PC}}\right\}
\end{aligned}
$$

Table 2 shows the flow rates equations that are satisfied with each Nodes. The balance equations consist of three groups, in order from top; "( i ) quantity of washing water" that is concerned to the displacement washing ratio DR value, "( ii ) chemical consistency of alkali (Na) components in the brown pulp stocks", and “( iii) chemical amount of alkali (Na) components in the brown pulp stocks". And, every alkali components contents were converted to the amount of "total alkali $\left(\right.$ as $\left.\mathrm{Na}_{2} \mathrm{O}\right)$ ". 
Table 4 Calculation settings : pulp concentrations (In \& Out), DF and DR values of each washing equipment.

\begin{tabular}{|c||c|c|c|c|c|c|}
\hline & $\begin{array}{c}\text { KP Digester } \\
\text { High heat } \\
\text { Washing zone }\end{array}$ & PDW & DW & $\begin{array}{c}\mathrm{O}_{2} \text { Bleach } \\
\text { Pre Washing } \\
\text { Filter }\end{array}$ & $\begin{array}{c}\text { DP } \\
\text { Washer }\end{array}$ & $\begin{array}{c}\text { Bleach Pre } \\
\text { Washing } \\
\text { Filter }\end{array}$ \\
\hline \hline In Pulp Consistency(\%) & 10 & 10 & 10 & 1.5 & 3 & 1.5 \\
\hline Out Pulp Consisyency(\%) & 10 & 10 & 10 & 15 & 30 & 15 \\
\hline DF (Dilution Factor: -) & 2.5 & 2.5 & 2.5 & 2.5 & 2.5 & 2.5 \\
\hline $\begin{array}{c}\text { DR(Displacement } \\
\text { Ratio:\%) }\end{array}$ & 93.5 & 87.0 & 87.0 & 68.0 & 58.0 & 68.0 \\
\hline
\end{tabular}

\begin{tabular}{|c|c|c|c|c|c|c|c|c|c|c|c|c|c|c|c|c|c|c|c|c|c|c|c|c|c|c|c|c|}
\hline & sc1 & $\mathrm{Sc}_{2}$ & $\mathrm{Sc}_{3}$ & SC4 & sc5 & sc6 & Sc7 & SC8 & sc9 & sc 10 & sc11 & $\mathrm{sc} 2$ & $\mathrm{SC}_{13}$ & $\mathrm{Sc}_{14}$ & sc15 & sc16 & sc17 & sc18 & sc19 & $s c 20$ & sc21 & $\mathrm{Sc}_{22}$ & sc23 & $\mathrm{SC}_{24}$ & sc25 & $\mathrm{SC} 26$ & $\mathrm{Sc}_{27}$ & Const \\
\hline Node 1 & -0.065 & 0 & 80 & 71 & 0 & 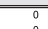 & 0 & $\overline{0}$ & 0 & $\overline{0}$ & $\overline{0}$ & 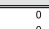 & -0.935 & 0 & 0 & $\overline{00}$ & 0 & 0 & $\overline{0}$ & 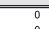 & 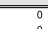 & 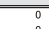 & 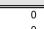 & 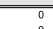 & 0 & 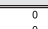 & 0 & 0 \\
\hline & $\begin{array}{l}0 \\
0\end{array}$ & & & $\begin{array}{r}-0.130 \\
0\end{array}$ & $\begin{aligned} & 1 \\
&-0.130\end{aligned}$ & & $\begin{array}{l}0 \\
0\end{array}$ & & & & $\begin{array}{l}0 \\
0\end{array}$ & $\begin{array}{l}0 \\
0\end{array}$ & & & $\begin{array}{r}-0.870 \\
0\end{array}$ & 0 & $-0.870^{\circ}$ & & & $\begin{array}{l}0 \\
0\end{array}$ & : & & & $\begin{array}{l}0 \\
0\end{array}$ & $\begin{array}{l}0 \\
0\end{array}$ & & $\begin{array}{l}0 \\
0 \\
0\end{array}$ & $\begin{array}{l}0 \\
0 \\
0\end{array}$ \\
\hline & & & & $\begin{array}{l}0 \\
0\end{array}$ & & & $\begin{array}{r}-0.320 \\
0\end{array}$ & & & -0.420 & $\stackrel{0}{1}$ & $\vdots$ & & & : & $\stackrel{0}{0}$ & & & & $\begin{array}{r}-0.680 \\
0\end{array}$ & : & & -0.580 & $\stackrel{0}{0}$ & $:$ & & : & $\begin{array}{l}0 \\
0\end{array}$ \\
\hline & 0 & & & 0 & 0 & 0 & 0 & 0 & 0 & 0 & 0 & 0 & & -1 & 0 & $\frac{0}{0}$ & & & $\frac{0}{0}$ & 0 & 0 & & $\frac{0}{0}$ & $\frac{0}{0}$ & 0 & & 0 & \\
\hline $\begin{array}{l}8 \\
9\end{array}$ & 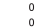 & & & : & $\stackrel{0}{0}$ & : & $\begin{array}{l}0 \\
0\end{array}$ & & & & : & : & & : & : & -1 & & -1 & : & $\begin{array}{l}0 \\
0\end{array}$ & : & & & : & : & & & \\
\hline 10 & & & & 0 & 0 & 0 & 0 & & & & 0 & : & & & 0 & 0 & & 1 & -1 & 0 & 0 & & & 0 & 0 & & & 0 \\
\hline . $\begin{array}{l}11 \\
12\end{array}$ & $\begin{array}{l}0 \\
0\end{array}$ & & & $\begin{array}{l}0 \\
0\end{array}$ & 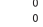 & $\begin{array}{l}0 \\
0\end{array}$ & $\begin{array}{l}0 \\
0\end{array}$ & & & & & $: 0$ & & & 0 & 0 & & & & $\begin{array}{l}1 \\
0\end{array}$ & 1 & & & 0 & : & & $\begin{array}{l}0 \\
0 \\
0\end{array}$ & $\begin{array}{l}0 \\
0\end{array}$ \\
\hline 13 & & & & & : & : & 0 & & 0 & & & 0 & & : & 0 & 0 & & & & 0 & 0 & & & -1 & 0 & & 0 & 0 \\
\hline 15 & 2.869 & 0 & & -2869 & 0 & 0 & $\frac{0}{0}$ & 0 & 0 & $\frac{0}{0}$ & 0 & 0 & $\begin{array}{l}3.754 \\
\end{array}$ & 0 & 0 & 0 & 0 & 0 & 0 & 0 & 0 & 0 & 0 & $\frac{1}{0}$ & $\frac{1}{0}$ & -3.754 & & 0 \\
\hline \begin{tabular}{l|l}
16 \\
17
\end{tabular} & 0 & & & $\begin{array}{r}2869 \\
0\end{array}$ & $\begin{array}{r}-2869 \\
2.869\end{array}$ & $\begin{array}{r}0 \\
-2889\end{array}$ & o & & & & : & : & $\begin{array}{l}0 \\
0\end{array}$ & $\begin{array}{r}-3.754 \\
0\end{array}$ & $\begin{array}{c}3.754 \\
0\end{array}$ & $\begin{array}{r}0 \\
-3.754\end{array}$ & 3.00 & : & & : & : & & & $\begin{array}{l}0 \\
0\end{array}$ & : & & & \\
\hline 18 & 0 & & & 0 & 0 & 2869 & -20.931 & 0 & & 0 & 0 & 0 & & $\therefore$ & 0 & 0 & 0 & 18.063 & 0 & 0 & 0 & & & 0 & 0 & & 0 & 0 \\
\hline $\begin{array}{l}19 \\
20 \\
20\end{array}$ & : & & \% & 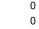 & : & $\begin{array}{l}0 \\
0\end{array}$ & $\begin{array}{r}20.931 \\
0\end{array}$ & $\begin{array}{l}-1.1806 \\
1.806\end{array}$ & $\begin{array}{r}0 \\
-1.806\end{array}$ & & $\begin{array}{l}0 \\
0\end{array}$ & : & & $\begin{array}{l}0 \\
0\end{array}$ & $\begin{array}{l}0 \\
0\end{array}$ & : & $\begin{array}{l}0 \\
0\end{array}$ & : & $\begin{array}{r}21.817 \\
0\end{array}$ & $\begin{array}{r}2.692 \\
0 \\
0\end{array}$ & $\begin{array}{l}0 \\
0\end{array}$ & $\begin{array}{l}0 \\
0\end{array}$ & 0 & $\begin{array}{l}0 \\
0 \\
0\end{array}$ & : & & $\begin{array}{l}0 \\
0 \\
0\end{array}$ & $\begin{array}{c}0 \\
-10.625\end{array}$ \\
\hline $\begin{array}{l}21 \\
22\end{array}$ & : & & : & : & : & : & $\begin{array}{l}0 \\
0\end{array}$ & : & $\begin{array}{r}1806 \\
0\end{array}$ & $\begin{array}{r}-10.306 \\
10.306\end{array}$ & $\begin{array}{r}0 \\
-0.744\end{array}$ & & & : & : & : & & : & : & $\begin{array}{l}0 \\
0\end{array}$ & $\begin{array}{r}8.500 \\
0\end{array}$ & $\begin{array}{r}0 \\
-11.192\end{array}$ & $\begin{array}{r}0.629 \\
1.629\end{array}$ & $\begin{array}{l}0 \\
0\end{array}$ & : & & $\begin{array}{l}0 \\
0 \\
0\end{array}$ & : \\
\hline 23 & 0 & & 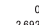 & 0 & 0 & 0 & 0 & 0 & 0 & 0 & 0.744 & -20.931 & & 0 & 0 & 0 & & & 0 & 0 & 0 & 0 & & 20.188 & 0 & & 0 & 0 \\
\hline 25 & 1 & 0 & 0 & 0 & 0 & 0 & 0 & 0 & 0 & 0 & 0 & 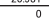 & 5 & 0 & 0 & 0 & 0 & 0 & 0 & 0 & 0 & 0 & 0 & 0 & 10 & 0 & 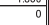 & 56.546 \\
\hline $\begin{array}{l}26 \\
26 \\
27\end{array}$ & 0 & & & $\begin{array}{l}0 \\
0\end{array}$ & 0 & : & 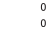 & & : & $:$ & & & & & 0 & & & & & : & 0 & & & : & : & , & $\begin{array}{llll}0 & 0 \\
0\end{array}$ & $\begin{array}{l}0 \\
0.00\end{array}$ \\
\hline
\end{tabular}

Fig. 8 Coefficients of matrix for countercurrent flow washing calculation.

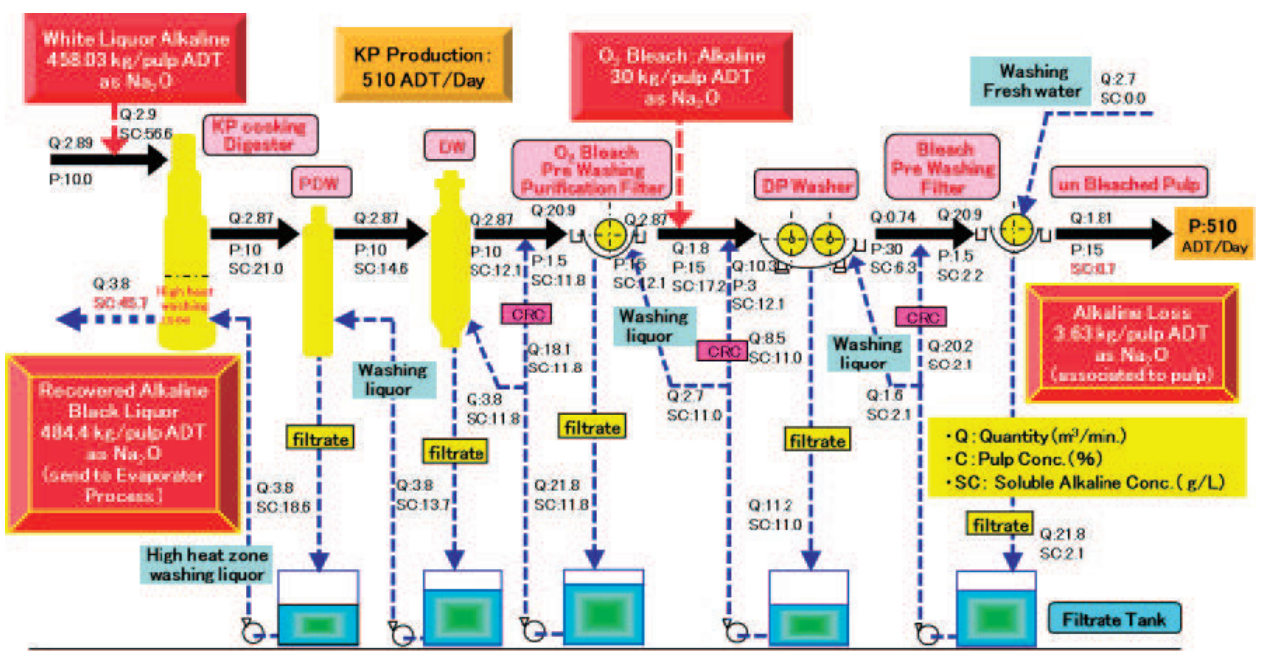

Fig. 9 Alkaline balance calculation of a countercurrent flow stock washing process.

Table 3 shows the variable names and the details of the calculation conditions, that were used in the washing simulation shown in the following sections. By the way, in the simulations, the production rate of the unbleached Kraft pulp (UKP) was assumed by 510 ADT/day. Also, in these calculations, it required to be given each dilution factor: DF values of the washing process and each consistency, that are supplied to and discharged from the six units of the washing equipment, in advance. Although duplication, the major setting conditions for the washing simulation were summarized in Table 4. In this calculation example, all dilution factors: DF values of the washing process were set to 2.5 , and the washing replacement ratio: DR values were set by reading the values from the graphs of Fig. 5, that are correspond to the targeted DF values.

From the above setting conditions, linear simultaneous equation that consist of individual 27 pieces of equations that including 27 unknown variables can be constructed. And the coefficient values of this multiple simultaneous equations were shown in the matrix table of Fig. 8. The horizontal direction shows the 27 unknown variables of the filtrates' chemical consistencies: SC $1 \sim$ SC 27 , that should be calculated, and the vertical direction shows 27 equations as a form of matrix, and the rightmost columns show the values that corresponds to the constant term of each equations.

5.1.2 Material balance calculation results of counter current flow washing model

The multiple simultaneous equation was solved nu- 
merically by PC, and Fig. 9 show the calculation results of the washing balance of "(B) countercurrent flow washing process" of KP process (the production rate of the unbleached Kraft pulp (UKP) is assumed 510 ADT/ day). Here, note that, for the pulp stocks washing process, the clean fresh water is supplied only one place to (6) Bleach pre washing filter of the upper-right corner in the figure, and all wash waters are filtrates that were discharged from the one previous stage's washing equipment, one by one, and repeat re-using them with the countercurrent flow washing. The calculation results of each flow line of Q: flow rate $\left(\mathrm{m}^{3} / \mathrm{min}\right)$, the pulp consistency (\%) : C, and SC: total alkali consistencies dissolved in the brown pulp stocks or filtrates ( $\mathrm{g}$ as $\mathrm{Na}_{2} \mathrm{O} /$ Liter) are indicated in the figure.

The calculation result of this simulation was follows; the washing water flow rate of the clean fresh water have to be supplied were $2.7 \mathrm{~m}^{3} / \mathrm{min}$, the flow rate that recovered as waste waters accompanied with the extracted black liquors etc. from KP cooking digester were $3.8 \mathrm{~m}^{3} / \mathrm{min}$, finally, the total alkali compounds that contained in the recovered filtrate were $484.4 \mathrm{~kg}^{(*)} / \mathrm{ADT}$, and the concentration of the chemical component became $45.7 \mathrm{~g}^{(*)} /$ Liter $(=4.57 \%)$. And, the loss amount of the total alkali compounds that are brought out from the washing system attached to the brown pulp stocks were $3.6 \mathrm{~kg}^{(*)} / \mathrm{ADT}$, and its consistency was calculated to be $0.7 \mathrm{~g}^{(*)} /$ Liter $(=0.07 \%)\left(^{(*)}:\right.$ as $\left.\mathrm{Na}_{2} \mathrm{O}\right)$.

Proceeding the washing process towards the upstream forward, the consistencies of the chemical components and the contamination states of the filtrates are increased and worsen gradually owing to the "countercurrent flow washing". However, it would not be a problem for the pulp stock washing operation, since the lesser contaminated filtrates are utilized always for the washing water compared to the pulp stocks to be washed.

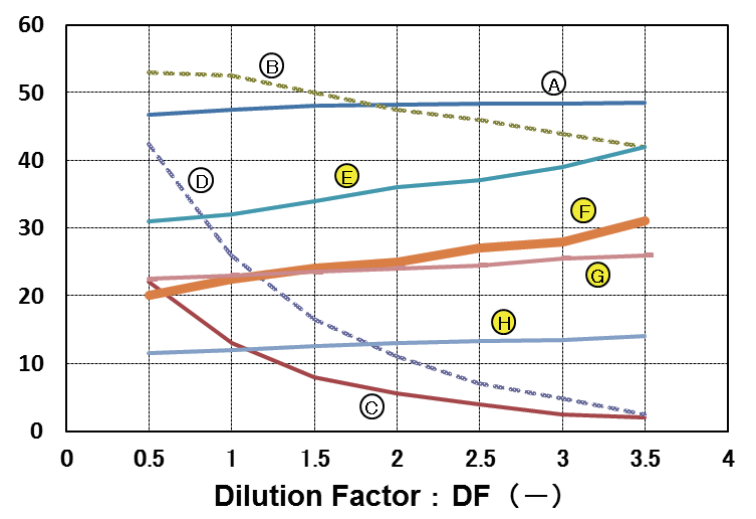

\subsubsection{Variation of calculation results due to DF value settings}

Next, in order to examine the influence of the DF value to the calculation results in the washing process, the value of dilution factor: DF were changed between 0.5 and 3.5 , in steps of 0.5 under the same condition settings with Section 5.1.1., and Fig. 10 shows the variation states of the main values. Here, the DF operating value of the six units of washing equipment were aligned all the same for the performance comparison. Incidentally, the calculation of different DF values settings for each washing equipment is possible, too.

In this figure, $\mathrm{F}$ is the clean water flow that required for the pulp stock washing $\left(\mathrm{m}^{3} / \mathrm{min}\right)$, (E) is the black liquor flow that were used for the washing water, and finally to be extracted from the Hi-heat washing zone of KP cooking digester $\left(\mathrm{m}^{3} / \mathrm{min}\right)$, (A) is the amount of the total alkali compounds that are send to the following evaporator equipment and to be recovered $\left(\mathrm{kg}^{(*)} / \mathrm{ADT}\right)$, (B) is its consistency $\left(\mathrm{g}^{(*)} /\right.$ Liter $)$, (C) is the loss amount of the total alkali compounds that were brought out attached to the brown pulp stocks $\left(\mathrm{kg}^{(*)} / \mathrm{ADT}\right)$, (D) is its consistency $\left(\mathrm{g}^{(*)} /\right.$ Liter), (G) is the amount of the total alkali compounds that were contained in the filtrates from the DP washer $\left(\mathrm{kg}^{(*)} / \mathrm{ADT}\right)$, (I) is the amount of the total alkali compounds that were contained in the filtrates from the Bleach pre-washing filter $\left(\mathrm{kg}^{(*)} / \mathrm{ADT}\right)\left({ }^{(*)}:\right.$ as $\left.\mathrm{Na}_{2} \mathrm{O}\right)$.

Furthermore, it can be understood from Fig. 10, that if the DF value of the dilution factor is increased, the amount of the recovered total alkali compounds (A)), that send to the following evaporator, increased accompanied to it. At the same time, the loss amount of the total alkaline compounds attached to the brown pulp stocks (C), that brought out from the washing system, are decreasing. However, on the contrary, the consistency of the total alkali compounds (B) of the finally recovered filtrates are decreased gradually, with the increase of the flow rates ( $(\mathbb{E})$ ). So, these trends resulted to in-

\footnotetext{
(A): Recovered Total-Alkaline amount $\left((*): \mathrm{as} \mathrm{Na}_{2} \mathrm{O}\right)$ send to Evaporator Equipment $(\times 1 / 10 \mathrm{~kg}(*) / \mathrm{ADT})$

(B): Recovered Total-Alkaline Concentration send to Evaporator Equipment $(g(*) /$ Liter $)$

(C): Brought out Total-Alkaline Loss amount contained to pulp stock $(\mathrm{kg}(*) / \mathrm{ADT})$

(D): Brought out Total-Alkaline Loss Concentration contained to pulp stock $(\times 10 \mathrm{~g}(*) /$ Liter $)$

(): Extracted Black Liquor Quantity from KP Digester High heat Washing zone $\left(\times 10 \mathrm{~m}^{3} / \mathrm{min}.\right)$

(E): Clean Washing Water Quantity $\left(\times 10 \mathrm{~m}^{3} / \mathrm{min}\right.$.)

(C): Total-Alkaline contain amount of filtrate out from DP(Double Pressure) Washer $(\mathrm{kg}(*) / \mathrm{ADT})$

(AT): Total-Alkaline contain amount of filtrate out from $\mathrm{O}_{2}$ Bleach Pre Washing Purification Filter $(\mathrm{kg}(*) / \mathrm{ADT})$
}

Fig. 10 Changing state of washing conditions according to the Dilution Factor (DF) setting. 
crease the cost of the heating steam usage to concentrate the black liquors in the following evaporator process.

\subsection{Cross flow washing}

\subsubsection{Modelling for cross flow washing}

In the KP washing process, although "(B) countercurrent flow washing" is applied, in general, it was investigated about how the washing states are changing, if the washing processes were replaced to "(A) cross flow washing" that was mentioned in Section 4.2. Fig. 11 shows the model diagram of "(A) cross flow washing" for the same process. This washing flow was assumed that, all six units of the washing equipment lines are supplied clean washing water only, as an extreme example.

The coefficient values of this multiple simultaneous equation were shown in the matrix table of Fig. 12 in the same shape as Fig. 8. In Fig. 12, and only the consistency value settings of the washing water suppling lines for the washing equipment and the coefficient values that related to the consistency control systems are changed (colored parts).

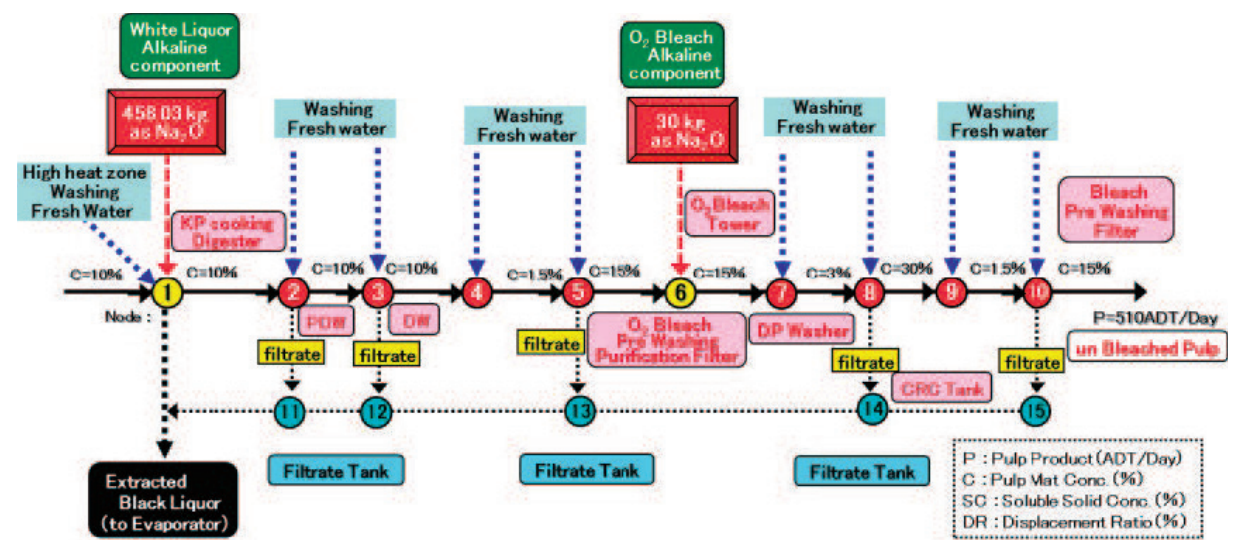

Fig. 11 Stock washing process model for a cross flow.

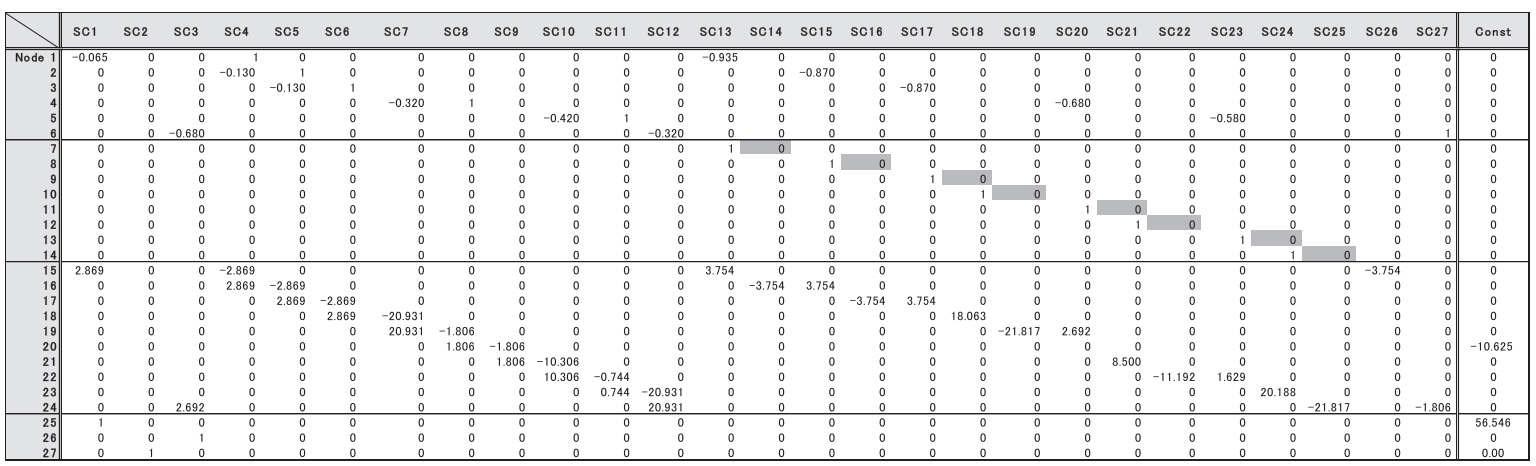

Fig. 12 Coefficients of matrix for cross flow washing calculation.

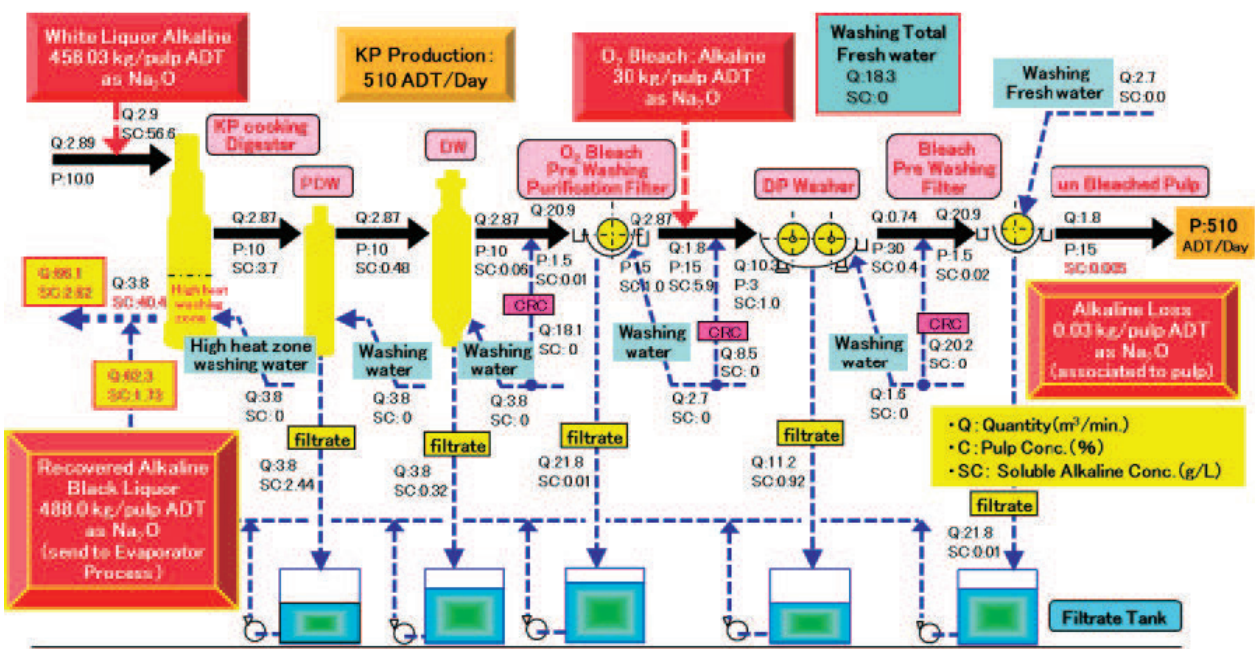

Fig. 13 Alkaline balance calculation of a cross flow stock washing process. 


\subsubsection{Material balance calculation results of cross flow washing model}

The multiple simultaneous equation was solved numerically in the same way. Fig. 13 show the calculation results of the washing balance of "(A) cross flow washing process" of KP process (the production rate of the unbleached Kraft pulp (UKP) is assumed 510 ADT/ day). It should be noted, that the dilution factor: DF values settings were all equal with Fig. 9, for the comparison with "(B) countercurrent flow washing" results that had been shown in Section 5.1.2.

Compared with the calculation results with Fig. 13 and Fig. 9, there are no differences in the amount of washing water that were used in each washing equipment, and the filtrates that were generated each equipment. However, the total alkali compounds consistencies brought in the washing equipment attached to the brown pulp stocks, and the total alkali compounds consistencies in the washing filtrates that generated from the washing equipment are quite different.

Finally, the calculation result of this simulation was follows; the washing water flow rate of the clean fresh wash water have to be supplied were $18.3 \mathrm{~m}^{3} / \mathrm{min}$. , all in total. Although the flow rate that recovered as waste water accompanied with the extracted black liquor etc. from KP cooking digester were large amount of $66.1 \mathrm{~m}^{3}$ / min, the total alkali compound consistency was $2.62 \mathrm{~g}^{(*)}$ / Liter and much lower. And the total alkali compounds that contained in the recovered filtrate were $488.0 \mathrm{~kg}^{(*)}$ / ADT, the loss amount of the total alkali compounds that were brought out from the washing system attached to the brown pulp stocks were $0.03 \mathrm{~kg}^{(*)} / \mathrm{ADT}$, and the concentration of the chemical component were calculated with $0.005 \mathrm{~g}^{(*)} / \operatorname{Liter}\left(^{(*)}:\right.$ as $\left.\mathrm{Na}_{2} \mathrm{O}\right)$.

\section{Considerations}

6.1 Comparison of washing flow quantity, recovery amounts of chemical compounds and its consistencies

The main calculated values of the two simulation results "(A) cross flow washing (Section 5.2.1)" and "(B) countercurrent flow washing (Section 5.1.2)" were summarized in tabular forms and compared in Table 5.

When the production rate of the unbleached pulp (UKP) was $510 \mathrm{ADT} /$ day, although the flow rate of the clean fresh water required for the pulp stock washing in “(B) countercurrent flow washing” was $2.7 \mathrm{~m}^{3} / \mathrm{min}$. at most, the flow rate was increased significantly to 18.3 $\mathrm{m}^{3} / \mathrm{min}$. (6.7 times) in the case of "(A) cross flow washing". Instead in the case of (A), the loss amount of the total alkali compounds that brought out from the washing system attached to the pulp stocks were only $0.03 \mathrm{~kg}$ (*) /ADT, and decreased excessively, against the amount of (B) $3.63 \mathrm{~kg}^{(*)} / \mathrm{ADT}$, the value of (B) decreased excessively than expected. Furthermore, the amount of the total alkali compounds that were recovered finally as black liquor was simulated $484.4 \mathrm{~kg}^{(*)} / \mathrm{ADT}$ in "(B) countercurrent flow washing", and the value in "(A) cross flow washing" was $488.0 \mathrm{~kg}^{(*)} / \mathrm{ADT}$, and there was no great difference $(+0.74 \%$ increase $)$ with them. However, against the chemical components' recovery consistency of (B) was simulated considerably high value of $45.7 \mathrm{~g}^{(*)} /$ Liter, the value of (A) was decreased significantly to $2.62 \mathrm{~g}^{(*)} /$ Liter ${ }^{(*)}:$ as $\left.\mathrm{Na}_{2} \mathrm{O}\right)$.

In other word, to apply "(B) countercurrent flow washing" to the washing process can expect the significant effect of reducing the expensive heating steam usage either, without worsen the washing states significantly of the pulp stocks, that is required to concentrate the black liquors in the following evaporator process.

Table 5 Comparison of washing method: Recovered alkaline amount and concentration.

\begin{tabular}{|c|c|c|c|}
\hline & \multirow{2}{*}{\begin{tabular}{||c||}
$\begin{array}{c}(A) \text { Cross flow } \\
\text { washing }\end{array}$ \\
18.3 \\
\end{tabular}} & \multirow{2}{*}{$\begin{array}{c}\text { (B) Countercurrent } \\
\text { flow washing } \\
2.7\end{array}$} \\
\hline $\begin{array}{c}\text { Washing } \\
\text { Fresh water Quantity }\end{array}$ & $\mathrm{m}^{3} / \mathrm{min}$ & & \\
\hline $\begin{array}{l}\text { Recovered Alkaline } \\
\text { send to Evaporator }\end{array}$ & $\begin{array}{c}\text { Total-Alkaline } \\
\text { kg as } \mathrm{Na}_{2} \mathrm{O} / \mathrm{ADT}\end{array}$ & \begin{tabular}{|l|}
488.0 \\
\end{tabular} & 484.4 \\
\hline \multirow{2}{*}{$\begin{array}{l}\text { Recovered Alkaline } \\
\text { States send to } \\
\text { Evaporator }\end{array}$} & Quantity ( $\mathrm{m}^{3} / \mathrm{min}$.) & 66.1 & 3.8 \\
\hline & $\begin{array}{c}\text { Soluble Total-Alkaline } \\
\left.\text { Solid Conc. ( } \mathrm{g} \text { as } \mathrm{Na}_{2} \mathrm{O} / \mathrm{Liter}\right) \\
\end{array}$ & 2.62 & 45.7 \\
\hline \multirow{2}{*}{$\begin{array}{l}\text { Alkaline Loss } \\
\text { acompanied to } \\
\text { pulp stock }\end{array}$} & \begin{tabular}{c|} 
Total-Alkaline \\
$\mathrm{kg}$ as $\mathrm{Na}_{2} \mathrm{O} / \mathrm{ADT}$
\end{tabular} & 0.03 & 3.63 \\
\hline & $\begin{array}{c}\text { Soluble Total-Alkaline } \\
\text { Solid Conc. ( } \mathrm{g} \text { as } \mathrm{Na}_{2} \mathrm{O} / \mathrm{Lit} \text { ) }\end{array}$ & 0.005 & 0.7 \\
\hline
\end{tabular}




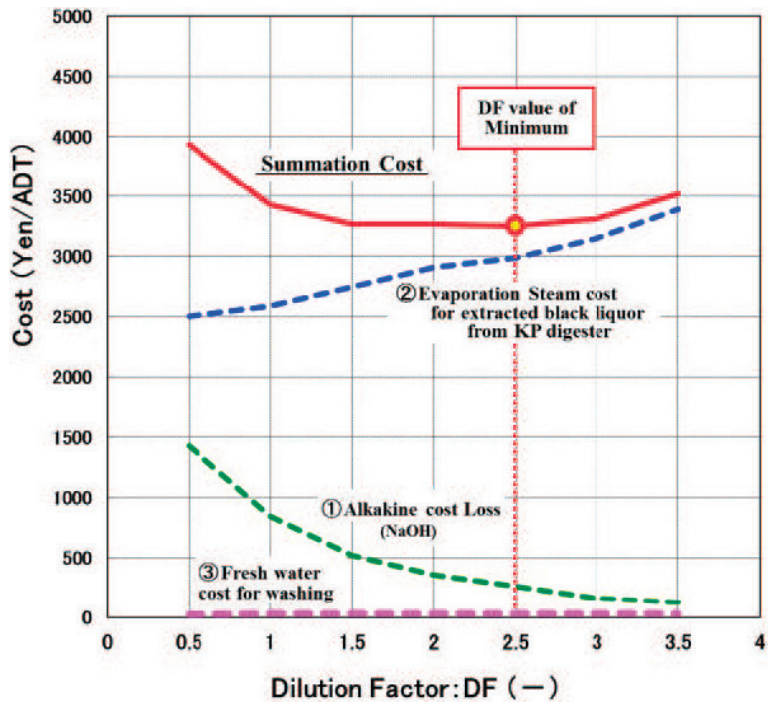

Fig. 14 Cost evaluation for Dilution Factor (DF) with a counter current flow stock washing process.

\subsection{Estimation for optimal Dilution Factor (DF) value}

Furthermore, utilizing the calculation results of the simulation of "(A) counter-current washing", that shown in Fig. 10 in Section 5.1.3, analyzed the most economical point of DF value in the KP washing process by changing the value of the dilution factor: DF. Here, the performance evaluation was carried out by considering about the following three cost losses in the washing process.

The three considerable changing cost losses are follows; (1) cost losses of the Na components (alkali compounds) that are brought out to the outside, attached to the unbleached brown pulp stocks not to be recovered in the following chemical recovery process, (2) cost losses of the low-pressure steam flow that were required for heating and to evaporate and condense the black liquor, that were extracted from $\mathrm{Hi}$-heat washing zone of $\mathrm{KP}$ cooking digester, by the following evaporator process, and (3) cost losses by the amount of flow rate of the clean fresh water that were required to wash the brown pulp stocks. And the analysis was done based on the sum of these three cost losses.

Further, in the cost loss calculation of (1), the amount of losses of the $\mathrm{Na}$ component are delivered by supplying, caustic soda $(\mathrm{NaOH})$ or sodium sulphate $\left(\mathrm{Na}_{2} \mathrm{SO}_{4}\right)$, and the chemical price was assumed $65 \mathrm{yen} / \mathrm{kg}$, here.

And in the cost loss calculation of (2), together with the assumption that, the "evaporation ratio" of the flow ratio of the heating steam against the supplying flow rate of the dilute black liquor was assumed $5.2^{7}$. Also, in the calculation of the steam costs for this evaporation process, it was assumed that $70 \%$ of the water contents of the flow rate of the dilute black liquor are evaporated by the six effects evaporator equipment of this recovery process, here.

The reason of the value $70 \%$ is the calculated results of the extracted black liquor from this KP cooking digester of the washing process does not include following items, in this balance calculation model;

- a large amount of lignin components weights that were dissolved by the digestion reaction from wood chips,

- chip moisture content' weights brought from wood chips,

- the condensed water amount of the steam that brought into the system when the wood chips are degassed and preheated in a steaming vessel etc.

Therefore, although the consistency of the dilute black liquor is lower than actual value, it can be estimated, that the ratio of the amount of evaporated water against the target flow rate is $\{1-(20 \% / 70 \%)\} \times 100 \doteqdot 70 \%$. Here, the dilution black liquor consistency that are supplied to the evaporator equipment is assumed $20 \%$, and the condensed black liquor consistency, after concentration process, is assumed $70 \%$.

Furthermore, the steam price that are used in the evaporator equipment is assumed 6 yen $/ \mathrm{kg}$, and clean fresh water that are used for the washing is assumed 0.03 yen $/ \mathrm{kg}$, here. And Fig. 14 show each value changes of (1), (2), (3) cost losses and calculated total sum cost losses.

In this figure, the vertical axis indicates the DF value of the dilution factor, and the horizontal axis indicate the calculated value of each cost losses of (1), (2), (3) and their total sum cost, and each values are connected by a straight line. The value of the cost loss (3) is very small, and it can be ignored with (1), (2) cost losses.

Finally, the transition of the total cost losses indicates a downward convex curve in case of Fig. 14, and the most optimal operation point that minimize the total cost value is estimated when the dilution factor is roughly around $\mathrm{DF} \doteqdot 2.5$. And this value is almost consistent with the operational experiences.

However, it should be noted that, the minimize point of DF values for the total cost loss is determined by the relationship of the reversed slope between the cost losses of (1) and the cost losses of (2), that are change accompanied with their each prices. Since the minimize point varies to the left and right by their conditions, it is necessary to pay attention to the judgement.

\section{Conclusion}

By construct the simulation model for the brown pulp stocks washing line of KP process, the mass balance of the chemical component amount that are contained and 
dissolved in the brown pulp stocks could be calculated, and utilizing the model investigated how they are changing, for example, the amounts and consistencies of chemical components that are recovered as the washing filtrates, and the loss of chemicals components that are brought away to the outside attached to the brown pulp stocks without recovered, according to the difference of the washing methods and so on.

As the result, it could be confirmed the superiority of the "countercurrent flow washing" method in KP washing process, and re-recognized the importance of washing process in Kraft pulp process.

\section{References}

1) R. H. Crotogino, N. A. Poirier and D. T. Trinh : The principal of pulp washing, Tappi Journal, June, 1987.

2) Perkins, J. H., Welsh, H. S. , and Mappus, J. H : Brown-stock washing efficiency-Displacement ratio method of determina tion, Tappi Journal, Vol. 37, No. 3, 1954.
3) Ricardo B. Santos, Peter W. Hart: Brown stock washing-A review of the literature, MWV Corp, 2014.

Peter W. Hart, Michael T. Brown : Brown stock washing-Fundamentals and Practices, Tappi, 2017.

4) Wakisaka : Washer Filter (theoretical part), Oji Paper co. , Ltd. , Central Technical Report, Vol. 166, No. 8, 1963.

5) Japan Tappi, Vol. 3 Washing, Screening and Bleaching of Pulp, Pulp and Paper Manufacture Series, 2000.

6) Y. Mori : Material balance calculation for a stock washing line and comparison of the recovered chemical component states, 59th. Japan Joint Automatic Control Conference, 2016.

7) Y. Mori : Concentration of KP black liquor by lowpressure steam and evaporation ratio with multi-effect vacuum evaporator, 61st Japan Joint Automatic Control Conference, 2018. 